\title{
Humanized Design of Portable Forestry Machinery
}

\author{
Jinglian Chen* \\ College of Arts and Design \\ Beijing Forestry University \\ Beijing, China, 100083 \\ Weiting Li \\ College of Arts and Design \\ Beijing Forestry University \\ Beijing, China, 100083
}

\author{
Wenbin Li \\ School of Technology \\ Beijing Forestry University \\ Beijing, China, 100083 \\ Minxing Cong \\ College of Arts and Design \\ Beijing Forestry University \\ Beijing, China, 100083
}

\begin{abstract}
In recent years, Portable forestry machinery is widely used for forestry operation in China and it is making great progress in terms of product range and functionality. However, many problems still remain in ergonomics and other humane aspects. This paper researched and explored the humanized design ideas and methods of portable forestry machinery after analyze the current man-machine interface parameters, modeling and colors of China's portable forestry machinery design. At last, the paper provides a reference for the future research of the portable forestry machinery.
\end{abstract}

Keywords-portable forestry machinery; ergonomics; humanized design; modeling

\section{INTRODUCTION}

Forestry machinery can be divided into portable machinery and self-propelled machinery. Portable forestry machinery widely used for forestry operation in China, mainly includes chain saw, brush cutter, pole type pruning saw, pneumatic extinguisher, forest fire extinguishing hand pump and so on [1]. In China, with complex terrain of numerous forest districts, poor road conditions, most large forestry equipment is difficult to access forest districts so that small- scale portable forestry machinery has a wide application market. Because the operators must work by carrying portable forestry machinery and this practice is heavy physical work, so the operators are very tired. Moreover, the high mental tension caused by cutting with chain saw, extinguishing with fire extinguisher and others leads to psychological load, which also cannot be ignored [2] [3]. Therefore, the humanized design of portable forestry machinery is particularly significant. The rationalization design of mechanical interface parameter, modeling and color can reduce the operator work load, which improves work efficiency of the operator and also operation comfort and security at the same time.

Fund program: The current study was supported by the Fundamental Research Funds for the Central Universities (YX2013-25) and the Specialized Research Fund for the Doctoral Program of Higher Education of China (20120014110012).

*Corresponding author: Jinglian Chen, jinglianchen@hotmail.com.
With relatively late development of forestry machinery, humanized design \& research of forestry machinery is great inferior to developed countries of the world. In 1970s, with implementation of the reform and opening up policy, China enhances foreign technical communication and cooperation and forestry machinery has a great development through technology introduction and new product development. Since the 1990s, China has emphasized the development of portable forestry machinery, product varieties and quantity of portable forestry machinery are on the rise and the quality of the products has been improved [4] [5]. Taking chain saw as an example, currently chain saw is introduced new technology, new material and new technology in different degrees and great progress has been made in product performance, service life and other aspects. However, compared with developed countries in the world, ergonomics and product humanization design still have larger gaps [6]. Thus, the study of portable forestry machinery has great practical significance and economic benefit from the view of humanized product design.

\section{HuMANIZATION DESIGN CONCEPT}

Humanized design refers to showing 'people-oriented' principles in the design. According to ergonomics, environmental psychology, aesthetic psychology and other subjects, it is to scientific ally learn about people's physiological characteristics, the characteristics of behavior psychology and visual perception and others, embody humanistic concern and design aesthetic and dynamic products suitable for the operators [7]. Consequently, in humanization design, product designers should put human factors as an important condition to consider during design and manufacture and finally realize mutual coordination and unity among 'man-environment--product'. Due to special working environment and operating environment of portable forestry machinery, working environment of the operator is relatively poor, thus, the humanized design of mutual coordination and unity among human, machine and environment is particularly important [1]. 


\section{HumANized Design Factors of PoRTABLE FORESTRY MACHINERY PRODUCTS}

Humanized design of portable forestry machinery products should mainly comply with the basic principles of ergonomics in combination with engineering technology, the principle of product semantics, psychology and so on [8]. It makes human and machine adapt each other and designs reasonable and efficient tools for people by parameter optimization and other ways. Hereinto, the following factors are mainly considered:

\section{A. The Man-Machine Operation Interface Parameters}

The man-machine operation interface parameters of portable forestry machinery mainly include mechanical structure size, weight, and others deciding operator work position. These parameters all take ergonomics as the basic principles. The operating requirements of the operator can be met only by basing design and consideration on the anthropometric data and physical labor capacity of Chinese human body, thereby improving work efficiency and reducing injury resulting from labor.

\section{1) Structural Dimension Parameters.}

In order to design suitable tools for China's forestry worker physiology and anatomy, the designers must fully understand the size of each part of human body and activity scope and are acquainted with working conditions of human body measurement data, especially the upper arm, forearm and palm size, as well as activity scope of upper limb range. For example, working length and handle length of forest fire extinguishing hand pump should relate to both hands grasping distance where arms can make the maximum operating force and the size of arm [9]. However, in China, enterprises often are lack of full consideration of the China's human body scale parameters during the design and production.

\section{2) Weight, Noise and Vibration.}

The weight of chain saw, pneumatic extinguisher, brush cutter has a significant influence on work fatigue of the operator. The weight of knapsack pneumatic extinguisher and forest fire extinguishing hand pump water bags not only affects the working load and working efficiency, and also gives the human body spinal disc pressure and the most serious condition is to make people fall over. [10] [11]. Therefore, reducing weight should be taken as a key measure of humanized design of the portable forestry machinery. In addition, vibration and noise lead to the operator fatigue and mental stress and the noise emitted by draught fan and chain saw cause serious environmental pollution. Vibration and noise control is a long-term and arduous task. Reduction of the vibration and noise from the view of technology innovation, exploration of vibration isolation problems and development of new comfortable protective equipment from the perspective of ergonomics, are subjects urgently needed to be solved.

\section{B. Modeling and Color}

The modeling and color of product are important content of humanized design. Since the1970s, Kansei Engineering becomes a major development direction in the field of ergonomics. It has been found that modeling and color designs of the product determined by the product functions not only have aesthetic effects, also have complex influence on the person's psychological, feeling and emotional experience. It is inevitable that forestry workers feel dull using portable forestry machinery to work with the strong labor intensity and repeat operation for a long time. However, the modeling of portable forestry machinery products on the market at present is too simple and color designs are excessively rough, in addition, the fieldwork is boring, which let the operator easily tired, not to mention, work comfort and humanization. If a product with rich change modeling, cleaner and softer color, and more simple and easy operation can be designed, the operator can has brand-new mental feeling and pleasure experience so as to increase the market competitiveness of products.

\section{1) Modeling.}

Modeling aesthetics is a factor that must be highlighted in product design. It not only improves the appearance of product, and makes people aesthetic mental pleasure and meets the needs for humanized design of users. At present, the modeling problems of domestic portable forestry machinery products are mainly: too simple overall modeling, messy details, the lack of unification, excessive stiff product shape, insufficiency for the change of line and surface and the lack of vitality. Modeling is lack of coordination and unification among family products of the same brand and brand image of the enterprise is deficiency of market competitiveness. Modeling and material of numerous portable forestry machinery products, such as pneumatic extinguisher, chain saw, directly adopting foreign product design, have not formed their own characteristics.

At present, with the increasing portable forestry machinery products at home and abroad, and increasingly fierce product competition, the aesthetic sense of people is increasingly improving, modeling design is particularly significant and design concept and moral spirit showed by product form are the crucial factors in consumer purchase incentives. Therefore, the modeling design of portable forestry machinery needs to be stressed, and the humanized design concept is applied to design and manufacture process to improve the quality and image of portable forestry machinery products.

\section{2) Color.}

The product use environment, function and other factors must be considered in the color design of products. Working environment of portable forestry machinery is mostly fieldwork with strong work intensity, machine work can produce noise and vibration, and fire suppression is also accompanied by smoke and others. These determine the color is unsuitable to use various hues and high purity color with sharp contrast. Complex color matching can make it difficult for the operator to concentrate, reduce the work 
efficiency. Color matching also has indication function. Color contrast can visually highlight important parts such as control elements, functional areas and so on, and guide the user's attention in order to improve the accuracy and efficiency.

Meanwhile, the color design is a powerful tool to create a brand image. Lots of enterprises apply the brand to product as a unified image in order to distinguish it from other brands. By comparison of color matching of the portable tool, it can be seen that Hitachi uses clam green and black, Bosch adopts blue green, black and a small amount of red and Dewalt uses the collocation of bright yellow and black. Steele uses orange, but Komatsu adopts vermilion among portable forestry machinery enterprises. However, color design of many domestic products still follows the design of foreign brand products and has not formed their own characteristics.

\section{Humanized Design Method Of Portable FORESTRY MACHINERY PRODUCTS}

\section{A. Man-machine Interface Geometry Parameters Optimization and Improvement of the Amenity and Safety of Products}

Through analysis of people's operation behavior, the main operation interface mechanical parameters (parameters such as diameter and length of the portable components and so on, and weight, work length, work height, etc.) are extracted; through human physiology and psychology test, the influence of different parameters on the human body work load is measured and analyzed to get interface parameters suitable for optimization [13]; through improvement, the geometric parameter database is gradually formed; through further improvement, uniform standards are formed which are used to guide the man-machine engineering design of portable forestry machinery products and improve the amenity and safety of products.

\section{B. Humanized Design of Shape and Color}

According to the principle of industrial product modeling, the form of portable forestry machinery is shaped. That is to say, modeling meets the product functions, accords with use features of people and complies with the rules of formal beauty. The operation for products can be instructed, warning functions for dangerous parts are made and comfortable and human working environment is constructed through overall color of machines and tools, and the color configuration of operating station. This is a German Stihl chain saw "Fig. 1". The different functional parts on the form of product are distinguished by volume segmentation. Full mechanical modeling of main body and handle highlights the sense of power, forms coordination with each other in the form. Sloping cambered surface modeling of handle form not only acts in cooperation with overall form, tilt angle of the handle is also suitable for human use, which furthest keeps wrist straight during operation, reduces fatigue caused by bend of the wrist [12]. The contrast between handle color and material, not only offers hints for the operation parts, but also skid-resistant mechanism used for contact surface on the hand is more suitable for operation by hands.
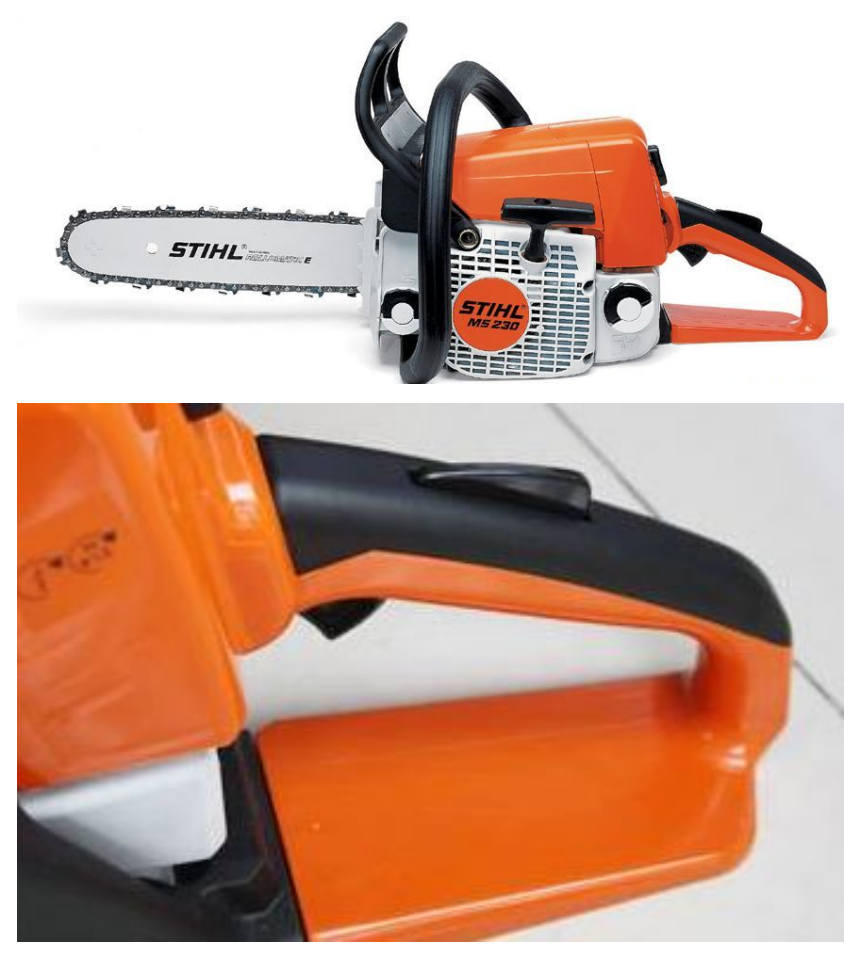

Fig. 1. German Stihl chain saw

\section{CONCLUSION}

Portable forestry machinery is widely used, its operation circumstances are relatively adverse and designers need to consider the structure, modeling and color design from the humanized perspective. Therefore, according to the human dimension data of forestry workers in China and operation types, the optimal design parameters are raised for ergonomics problems of the portable forestry machinery operation. The humanized design is realized, and safety and comfort of the operation are improved with overall consideration over the user's emotional experience and aesthetic factors.

\section{REFERENCES}

[1] Li Wenbin, Zhao Guangjie, Yin Ning. Progress in Forestry Engineering Research [M], China Environmental Science Press, 2005

[2] Li Yanjun, Piao Jinbo, Sun Jingyu. Negative Psychology often occurred at Forest Fire Suppression and Measures [J]. Forest Fire Prevention, 2006, 1: 26-27

[3] Aisbett, B., Wolkowa, A., Sprajcer, M., Ferguson, S., A. “Awake, smoky, and hot": Providing an evidence-base for managing the risks associated with occupational stressors encountered by wildland firefighters [J]. Applied Ergonomics, 2012: 1-10.

[4] Zheng Dehui. Simple Analysis of the Development and Application of Forestry Machinery [J], 2009, 27: 483-484.

[5] Chen Dawen. The Present Situation and Development of Forestry Machinery in China $[\mathrm{J}]$. Forestry Machinery and Woodworking Equipment, 1996, 2: 4-5. 
[6] Tong Qinghui. The Discussion for the Development of Forestry Machinery in Fujian Province, 2009, 37(4): Forestry Machinery and Woodworking Equipment, 4-7, 12.

[7] He Xiaoyou, Xie Yunfeng. Humanized Design [M]. Nanjing, Jiangsu Fine Arts Publishing House, 2001.

[8] Xia Zhiliang, Ye Zhenhe, Li Xin. Humanized Design Study of Coal Mine Machinery Products [J], Packaging Engineering Vo1. 29 No.4 2008. 0

[9] Chen.JL, Li.WB, Wang. Y. Study on man-machine interface of forest fire extinguishing hand pump based on operating force and SEMG, Proceedings of The 38th International Conference On Computers And Industrial Engineering (CIE38), 2008, 1-3: 2244-2247

[10] Chen Jinglian, Li Wenbin, Zhao Xiaoxiao, Research on Spinal Biomechanics Borne by Water Bags in Forest Fire Suppression, Journal of Beijing Forestry University, 2010, 32(3): 176-179

[11] Chen.JL, Li.WB, Ma. LF. Effects of water bag of forest fire suppression hand pump on body balance[C]. Proceedings of the 2 nd International Symposium on Computational Intelligence and Design (ISCID 2009), 2009, 2: 429-433

[12] Benjamin Niebl. Methods, standards and work, Beijing: Tsinghua University Press, 2009:115-190

[13] Linjie Wang, Wenbin Li, Jinglian Chen. Ergonomic evaluation of the operating characteristics of the $6 \mathrm{MF}-30$ portable pneumatic extinguisher[J], Applied Ergonomics, 2015, 51: 39-43. 